\title{
The Ontology of Uncertainty in Finance: The Normative Legacy of General Equilibrium
}

\author{
Ivan Boldyrev ${ }^{1}$ (D) \\ Published online: 28 March 2019 \\ (c) The Author(s) 2019
}

\begin{abstract}
This paper considers in detail the ontological and normative presuppositions of the state-contingent approach to pricing commodities first introduced by Arrow (Le rôle des valeurs boursières pour la répartition la meilleure des risques. Econométrie, Centre National de la Recherche Scientifique, Paris, 1953) in his model of general equilibrium under uncertainty, which became a milestone in the theory of finance. By contextualizing Arrow's fundamental contribution and subsequent developments in finance, it demonstrates how this new conceptual framework implied certain technologies-both intellectual and financial. In showing how theoretical thinking about finance was underlying institutional developments in finance, this paper complements the familiar narrative of the performativity of economics.
\end{abstract}

Keywords Performativity $\cdot$ General equilibrium $\cdot$ State pricing approach $\cdot$ Arrow securities $\cdot$ Market socialism $\cdot$ Normativity

Finance - as a sector of the economy and as a form of economic knowledge (this ambiguity is crucial for my analysis) - has relatively recently drawn scholarly attention. One of the obvious reasons for that is the huge rise of the financial sector, a notorious 'financialization,' coupled with (both real and expected or imaginary) global instabilities associated with it. But this does not explain the renewed attention paid to the theory of finance-or, one can also say, to the economic theory underlying finance.

In his Critique of Hegel's Philosophy of Right, Marx demonstrated that the criticism of a certain form of knowledge is a prerequisite of social criticism, because knowledge (in Marx's case-philosophy) is an ideal extension of the real social world. By scrutinizing the abstractions of social science, for example the ontology of financial models, we thus contribute to a better understanding of the rationales behind real financial worlds. I will demonstrate that certain concepts in (financial) economics are to be interpreted as social technologies aimed at solving some specific problems.

Ivan Boldyrev

i.boldyrev@fm.ru.nl

1 Department of Economics, Institute for Management Research, Radboud University Nijmegen, Postbus 9108, 6500 HK Nijmegen, The Netherlands
It is in this way that economic models become part of the institutional infrastructure of markets.

In his superb and wide-ranging history of financial economics, focused on the notion of performativity, MacKenzie (2006a, b) reformulates this insight in a more precise sense, by treating theoretical finance as a set of important technologies that radically transformed the institutional structure and functioning of the financial markets.

MacKenzie, however, does not mention one important stream of literature which, however, one could argue, has become foundational for the theory of finance. This stream is connected to the seminal contribution of Arrow (1953) which initiated the general equilibrium analysis in finance. In this paper, I will argue that Arrow inaugurated a new way of structuring the world in order to make sense of what finance was about. I will also consider Arrow's approach in the context of his other writings, which should help demonstrate how it may be linked to the idea of performativity, which should complement the familiar discussion of the Black-Scholes model. 


\section{Arrow on Finance}

Arrow's short paper, conceived as an extention of the general equilibrium analysis to the case of uncertainty ${ }^{1}$ and published, curiously, before the now classical general equilibrium model (Arrow and Debreu 1954) appeared in print, has become a milestone in financial economics. How could that happen?

Once the need was perceived to go beyond certainty in the standard framework of rational choice and general equilibrium, finance became the obvious domain of application: social technologies of financial world routinely deal with uncertain future.

The uncertain world in this framework is a world partitioned into various possible states. A timing problem is immediate here, but since we are in a model world, we either simply assume that we are at a point 0 of the present and there is only uncertainty about the future states of the world, or we consider the complete 'history' of the world from its inception. What is important in this representation is the idea that the there are mutually exclusive subsets of states (usually called 'events') which would form a partition and allow us to represent the future as a tree of possibilities, fully known to us at the outset. This description of uncertainty looks much more 'fundamental' and general than any other of the kind (see Drèze 1974).

The market for contingent commodities is a natural generalization of the familiar general equilibrium logic, the most 'general' general equilibrium one might have-and the triumph of formalization (Duffie and Sonnenschein 1989). In this economy, agents buy and sell not ordinary, but contingent commodities, and the efficient allocation is obtained in the 'beginning' of the world, before the 'true' state of nature is revealed. They buy not an umbrella, but, say, an umbrella in Paris, at a certain date, given the fact that it rains. ${ }^{2}$

Starting with contingent commodities, Arrow demonstrated that we can rule out the (fully utopian) idea of having markets for each commodity in each state of the world and thus reduce the complexity associated with uncertainty. Arrow's idea was to substitute the complete set of markets (for each contingent commodity) by the combination of

\footnotetext{
${ }^{1}$ Here and elsewhere, I do not distinguish 'risk' and 'uncertainty' in the well-known Knightian sense-following my protagonist, Arrow, who worked toward 'displacing' the latter with the former (Schliesser 2012). This does not mean that I endorse this displacement, moreover, the story I am going to tell should further reinforce this important distinction.

2 In a lucid depiction by Radner (1970, p. 455), "a 'market' is organized before the beginning of the physical history of the economic system. An elementary contract in this market will consist of the purchase (or sale) of some specified number of units of a specified commodity to be delivered at a specified location and date, if and only if a specified elementary event occurs."
}

securities trading and spot markets in commodities after the uncertainty is revealed. With a complete set of securities markets (for each state of the world, there is an independent security dividend vector), any consumption plan can thus be financed with certainty. Crucially, each agent in Arrow-Debreu economy has the same information-and the same correct beliefs-about the equilibrium spot prices at all the future dates. ${ }^{3}$

Thus, the very existence of financial markets, the existence of securities trading, achieved the most fundamental theoretical justification. On Arrow's view, finance was exactly about risk and the 'allocation of risk-bearing', that is, exchanging financial securities that 'cover' different states of the world. In the 1960s, this approach was adopted for financial economics by Hirshleifer $(1965,1966)$ and Myers (1968).

Arrow coined the idea of special 'Arrow securities' paying one unit of wealth if a given state occurs and nothing otherwise. He recalled the genealogy himself:

In trying to incorporate uncertainty into general equilibrium theory, I was led by the Wald-Savage viewpoint to consider an elementary decision as one that took a unit value for one state of nature and zero elsewhere; thus all general decisions could be regarded as bundles of elementary decisions. (Arrow 1983, p. 47) ${ }^{4}$

This code-like treatment ${ }^{5}$ also provided a very elementary and intuitive basis for subsequent formalization. The set of Arrow securities forms a basis in the vector space of all payoffs: each particular asset can be represented as a portfolio of Arrow securities. Thus, the simple intuitions of risk and return are paired with a linear mathematical structure. This partition of the world transforms all scalar variables into vectors: payoff of a particular asset becomes a vector, its elements being payoffs for this asset in a particular states of the world, while portfolios of assets are immediately formalized as vectors as well. Each portfolio becomes an instrument for dealing with possible future states.

In a perfect world of 'complete market' (one can buy an Arrow security for each possible future state), a portfolio of Arrow securities forms a benchmark for valuing each particular asset. Moreover, Arrow-Debreu prices (that is, prices of Arrow securities) play a key role in this context. In a very basic sense, they are used to 'price' the states of the world: by paying a particular amount for an Arrow security,

\footnotetext{
${ }^{3}$ On Duffie and Sonnenschein's (1989) interpretation, this also amounts to the idea of a fulfilled expectations equilibrium.

${ }^{4}$ In Savage (1954/1972, p. 9) we find a definition of a state of the world as a description leaving no relevant aspect of the world undescribed and of events as sets of states.

5 On Arrow securities as a code see in more detail: Boldyrev (2016).
} 
one pays for certainty in acquiring one unit of wealth in a particular state-that is why they are simply referred to as 'state prices', reflecting values of particular states for a rational actor. Uncertainty is thus 'priced', and the future becomes 'marketed' in a very deep sense of the word: the bits of future become subject to optimal allocation. This has consequences for the basics of the modern finance: It is relatively easy to show that for the famous (and essential) no-arbitrage condition in financial economics to hold, it is necessary and sufficient that a nonnegative vector of state prices exists such that each asset is priced by its returns weighed by those state prices (Varian 1987).

\subsection{What Role Did Arrow's Theory Play?}

First and foremost, Arrow and Debreu ${ }^{6}$ provided the most general framework available for dealing with asset pricing problems. If general equilibrium was treated as the most basic structure of all rigorous economics, the same should be true for financial economics as well. The lacking foundations of finance were finally discovered.

Second, and equally general, Arrow's argument demonstrated the precise role played by financial securities and, generally, by financial markets. Instead of accounting for every possible state of the world, it promised a radical reduction of complexity. Securities were considered as mathematical machines reallocating risks and adjusting the world to the changes in its structure constantly supplied every time new events arrive, that is, every time the uncertainty is replaced by certainty.

Finally, Arrow's argument suggested a set of heuristic strategies-or technologies-to complete the market. In the incomplete market world, the investors are allowed to change their portfolio structures over time and to apply dynamic trading strategies (Rubinstein 1987, 2006). This immediately leads to the Black-Scholes argument, in which only two assets are used to replicate the payoffs of any derivative asset. Arbitrage-free pricing of derivatives, establishing an 'equilibrium' benchmark for them, was thus a direct heir of Arrow's approach. This new technology has become very powerful, and it was this idea that finally was realized in the Black-Scholes pricing scheme. I wish to dwell on this role of Arrow's theory.

\footnotetext{
6 The question of priority is a difficult one. Arrow (1953) is the first formulation of the framework with the ideas of state pricing and spanning, while Debreu (1959) is a more general treatment integrating production and multi-period framework. In financial economics, Arrow's paper is mostly cited, while Debreu is credited with establishing the ultimate general equilibrium results on the highest level of generality.
}

\section{Performativity of General Equilibrium?}

General equilibrium analysis is a rigorous theory of the economy as a whole. As such, it was associated-in fact, very early, starting from its founder, Walras himself and then from scholars such as Barone (1908/1935) — with a normative ideal of perfectly planned economy. General equilibrium provided both the overall image of an ideally functioning system of markets and some sort of a cognitive infrastructure, set of techniques (of which the most immediate was the very equilibration of supply and demand-be it through an auctioneer or, later, through the 'central planning board') that would allow an equilibrium to be achieved - and thus 'performed'. How does Arrow fit into this picture?

Interestingly, the genuine techniques of general equilibrium analysis-fixed-point theorems-were also used at that time in the context of performativity - in the guise of a selffulfilling prophecy. In particular, Grunberg and Modigliani (1954) used it to demonstrate that public predictions may turn out to be correct, since there exists at least one (fixed) point at which the predicted parameter is actually observed (see also Hands 1990). But I would like to dwell on those applications that were more immediately connected to the normative interpretation of general equilibrium.

Recently, Eric Schliesser (2012) has demonstrated in detail that Arrow played a significant role in 'displacing' the idea of unmeasurable uncertainty-first by his influential survey paper (Arrow 1951) and then by his model of contingent commodities in which subjective probabilities of states of the world were assumed as being known by the agents. ${ }^{7}$

Underlying Schliesser's illuminating analysis is the idea that these displacements, whereby fundamental (or, in his parlance, 'metaphysical') uncertainty of the social world turned into quantifiable risk or formalizable randomness, are due to the normative policy concerns which require much less ambiguity than the Knightian (or Keynesian) concept of uncertainty could possibly deliver.

It is this element, which I find crucial in Arrow's approach, but which is rarely appreciated. For Arrow in the 1950s, a significant element of the theoretical programme in economics was to find an unambiguous normative welfare benchmark (hence such an attention paid to the proofs of the welfare theorems) — an idealized representation of markets

\footnotetext{
${ }^{7}$ Schliesser also notes that Arrow (1951), curiously, opened up another strategy by referring to Alchian (1950) who had suggested taming uncertainty in a more sophisticated way-by reinterpreting it not as quantifiable risk, but as randomness. Alchian suggested modeling decisions in face of fundamental uncertainty as steps in a random sequence. This, Schliesser (2012) argues, paved the way to the more sophisticated 'displacement strategy' that then grew into the theory of efficient markets as stochastic processes.
} 
that would allow to look at the real-world inefficiencies and deviations from this vision.

Indeed, Arrow's attitude toward his model of uncertainty has been compatible with his overall idea of general equilibrium:

This general equilibrium or, equivalently, the notion of ideal insurance markets, can act as a normative background for evaluating the efficiency of risk-bearing in the real world. (Arrow 1966, p. 269)

At the same time, commentators agree that both Arrow (1953) and Black and Scholes (1973) made unreasonable assumptions, sometimes bordering on insanity: in the former case, for the equilibrium to be achieved, even with the introduction of securities, the agents should correctly predict the state prices, while in the latter case constant volatility is assumed; indeed, the two assumptions are equivalent (Rubinstein 2006). How can we circumvent the unrealistic assumptions in these financial models? Or else how can we account for them?

One important feature of this lack of realism is an internal coherence, or closure, of the models: once we assume the perfect foresight or the constant volatility, the model does its work perfectly well. Perhaps for this reason equilibrium models of this kind are notoriously normative: they describe an ideal state of affairs and they invite us to find ways to achieve this benchmark.

If we recall what kind of work Arrow was doing in 1950s and 1960s, along with other prominent economists, such as Tjalling Koopmans and Leonid Hurwicz (see the general account in Mirowski 2002), we will better see the blueprints of this research program. Rationality in the Cowles commission has been reinterpreted as a normative ideal to be followed, rather than a descriptive empirical theory (Herfeld 2018), while the idea of general equilibrium was accompanied by a precise welfarist interpretation which gave it an explicit normative meaning. The genealogy of general equilibrium economics and its intimate links to market socialism (Lange 1936) clearly associate the very notion of equilibrium with a planning tool.

Now, as shown elsewhere (Boldyrev and Ushakov 2016), the overarching view of market socialists was very early recognized as an excessively ambitious enterprise. And stillwhile general equilibrium was never implemented-it was intended to be implemented. Whether one wished to use it literally, as a planning tool, or just as a benchmark, it was believed to be the best representation of socially optimal state of affairs. The plethora of approaches relinquishing some key assumptions (such as the one of perfect or symmetric information), including, interestingly, Arrow (1963) himself, led to the emergence of whole new fields of research, in which, again, the optimality of the general equilibrium, its normative status were never questioned.
These transformations of economics also involved-and inspired - a set of new approaches to the problem of arriving at equilibrium. If the total planning, performed by the omniscient Walrasian auctioneer was unattainable ${ }^{8}$ still some more piecemeal approaches could be tried out. One direction most immediately connected to the general equilibrium program — via the work of Hurwicz-was mechanism design that involved game-theoretic formulations, but also was conceptually connected to the general equilibrium literature.

I suggest that we analyze Arrow's contribution in this particular context. The dynamics is analogous: theoretical foundations laid by Arrow implied that perfect planning and perfect competition are indistinguishable and that it is helpful to look for the conditions a real economy must fulfill in order for general equilibrium to be attainable (this was also, arguably, the content of the so-called 'stability of equilibrium' literature). Note that Arrow's (1953) analysis of uncertainty is done with the same aim: it established quasiconcavity of utility functions (that is, individual risk aversion) as a sufficient condition of the viability of competitive equilibrium. ${ }^{9}$

That is why the modifications in the general equilibrium programme should be considered both from a theoretical and from a normative, or political, point of view. It was not just a question of 'integrating' uncertainty into general equilibrium theory-it was, at the same time, the question of mastering, or governing, uncertainty —of social technologies that might be helpful in this.

Uncertainty was, of course, perceived as a challenge for any planning paradigm, including a market socialist one. I omit here the discussion of the different types of uncertainty - in particular uncertainty of environment vs. uncertainty about the actions of other agents. This was later emphasized by Radner (1968) who tried to reformulate Arrow's approach and to 'save' the major results in the case of heterogeneous information. ${ }^{10}$ Just note that, in a sense, the game-theoretic mechanism design reformulation of general equilibrium analysis accounts for precisely this difference. The notion of incentive compatibility used in the game-theoretic literature is a technology aimed at overcoming the uncertainty about the actions of other agents. An almost simultaneous emergence of Sonnenschein-Mantel-Debreu results, which were disastrous for the general equilibrium

\footnotetext{
8 The analysis by Arrow, Hurwicz, Scarf and, finally, SonnenscheinMantel-Debreu implied that, in general, it is, indeed, the case. See Boldyrev and Ushakov (2016) for more historical details.

9 As it later turned out (and is noted by Arrow in the English version of his paper-see Arrow 1964), this condition is inessential.

${ }^{10}$ See also an incisive comment in Schliesser (2016).
} 
theory (see on that Rizvi 1994, 2006), also contributed to this move from general equilibrium to game theory.

Arrow's version of the market socialist argument introduced a set of ingenious techniques to master the uncertainty. A traditional form of market socialism implied that markets (or a planning mechanism fully imitating markets) could solve the allocation problem in an optimal way. In case of (always measurable) uncertainty, the problem became still more intricate: in this more complex structure of the world, the risk became the major issue. The actual power of Arrow's argument in this sphere lies not solely in 'marketization' of risks, but also in using financial securities as substitutes for (missing) markets.

It was Arrow who first introduced a new element into the ontology of economic models. A more general term for this new element of the economic world is 'contingent claim', that is, a contract attached to some uncertain event. The boom of the options market in the 1970s made it possible that interest of economists moved from the world of 'deterministic' demand and supply to the (arguably more general) idea of contingent claims.

We know how things developed in financial economics: Black, Scholes and Merton constructed an arbitrage-free pricing theory, in which rational agents reconsidered their portfolios at each moment of time and in which this dynamic hedging strategy was used as a technology to complete the market (Rubinstein 2006). In fact, the notion of equilibrium, of complete market, and of the lack of arbitrage could be used interchangeably as normative blueprints for a socially optimal financial system. Moreover, the most mathematically elaborate version of Black-Scholes analysis (Harrison and Kreps 1979), which treats uncertainty as a stochastic process, explicitly draws on Arrow's idea of 'spanning, 11 and complete markets. In this approach, arbitrage-free pricing of contingent claims involves re-arranging the probabilities of agents so that an arbitrage-free price of a security is equal to its expected price.

And while the agents in the financial sector, who are constantly seeking new profit opportunities, are as remote as possible from the agents in a perfectly planned socialist economy, accepting equilibrium prices set by the Central Planning Board, the analysis of MacKenzie (2006a, b) suggests that the distance might indeed be not so big. In fact, the agents on financial markets were, perhaps on a smaller scale, guided in their decisions by the 'equilibrium' technologies-or collective calculation devices-designed by financial economists. This guidance also helped legitimize option markets as a way to additionally hedge individual risks. But the key was, again, a rational-equilibrium,

\footnotetext{
11 A 'span' of a given security refers to the set of cash flows (and,
} thus, of consumption possibilities) generated by this security. arbitrage-free-pricing, the cornerstone of neoclassical economics.

These performative effects were also linked to the fact that the assumptions underlying the model-referring to some social facts-were becoming more realistic:

To the extent that the availability of the Black-ScholesMerton model played a part in the processes reducing transaction costs, the increased capacity to exploit discrepancies [between theoretical and real prices] was a performative effect of the model because the model facilitated the trading that moved patterns of prices towards its postulates. (MacKenzie 2006a, p. 48).

The surprising effects of financial economics on the financial sector thus exemplify two tendencies at work: an authority of economists and economic knowledge (see the recent overview in Hirschman and Popp Berman 2014); and the tendency of economists themselves to infer unambiguous and clear normative guidance from the ideal pictures of optimality they draw in their models. ${ }^{12}$

\section{Taking stock}

For the unsophisticated reader, the description of the world provided by Arrow (1953) seems bizarre. In assuming full knowledge of the future probabilities, it demonstrates 'a cavalier treatment of how agents arrive at their expectations' (Duffie and Sonnenschein 1989, p. 590) and are thus able to coordinate their actions. Its Wittgensteinian logical structuring of the world of (future uncertain) events, however, was in line with a general tendency of economists to rationalize the real world-or at least to come up with normative ideas envisaging possible ways of such a rationalization. The idea of complete markets reappeared not only in finance, but also in macroeconomics, where representative agent models with rational expectations did not differ much neither from the idea of a complete market ${ }^{13}$ nor, at least formally, from a Soviet mathematical economics concepts of planning (Hands 2016).

As for the financial economics, this normative dimension turned out to play an important role as well. Arrow's notions of complete markets, spanning, or elementary

\footnotetext{
12 Cf. a recent characteristic statement by Jean Tirole (2017, p. 86): 'More than other social sciences, economics claims to be normative; it aspires to "change the world."

13 "When one unpacked the "expectations" language of the rational expectations literature, it turned out that these models assumed that agents formed expectations of futures and contingency prices that were consistent with the aggregate plans being made, and hence were in fact competitive general equilibrium prices in a model of complete futures and contingency markets.' (Foley 1999, 90).
} 
securities were not just concepts used to conveniently formalize abstract ideas of resource (here: risk) allocation. Their immediate implications were the proliferation of contingent claims analysis, arbitrage-free pricing methods, the idea of risk-neutral pricing - the technologies that were used to bring the disequilibrium world of financial assets closer to its equilibrium portrayal and, in this sense, to 'perform' financial economics (MacKenzie 2006a). As Idabouk (2010, p. 139) notes,

the mere fact that the construction of Mathematical Finance was interwoven with financial engineering concerns stresses the normative role of mathematical models also from the standpoint of financial practice.

So, the lessons we can draw from this historical sketch are twofold. The first one urges us to rethink intellectual genealogy of modern finance and to remember that both its technical aspects and its deeper intellectual commitments owe a lot to the mainstream economics as it crystallized at places such as Cowles commission in the 1950-1960s, with a heavy influence of market socialism and (perhaps implicit) normative vision of its own role as science. Second, and related to that: economic/financial concepts, even the most abstract mathematical ones, are often entangled with certain social technologies, with rules and practices implied by the models, with ways to implement the ideas set forth in the formal mathematical frameworks and expressed in a normative way that prompts such attempts at implementation. This makes the initial ambiguity of the word 'finance' not so ambiguous, after all.

\section{Compliance with Ethical Standards}

Conflict of interest The author declares that he has no conflict of interest.

Research Involving Human Participants and/or Animals This paper does not contain any studies with human participants or animals performed by its author.

Open Access This article is distributed under the terms of the Creative Commons Attribution 4.0 International License (http://creativeco mmons.org/licenses/by/4.0/), which permits unrestricted use, distribution, and reproduction in any medium, provided you give appropriate credit to the original author(s) and the source, provide a link to the Creative Commons license, and indicate if changes were made.

\section{References}

Alchian A (1950) Uncertainty, evolution, and economic theory. J Polit Econ 58(3):211-221

Arrow KJ (1951) Alternative approaches to the theory of choice in risk-taking situations. Econometrica 19(4):401-437
Arrow KJ (1953) Le rôle des valeurs boursières pour la répartition la meilleure des risques. Econométrie. Centre National de la Recherche Scientifique, Paris, pp 41-48

Arrow KJ (1963) Uncertainty and the welfare economics of medical care. Am Econ Rev 53(5):941-973

Arrow KJ (1964) The role of securities in the optimal allocation of risk-bearing. Rev Econ Stud 31(2):91-96

Arrow KJ (1966) Exposition of the theory of choice under uncertainty. Synthese 16:253-269

Arrow KJ (1983) Collected papers, vol 2. The Belknap Press of Harvard University Press, Cambridge

Arrow KJ, Debreu G (1954) Existence of an equilibrium for a competitive economy. Econometrica 22:265-290

Barone E (1908/1935) The Ministry of production in the collectivist state. In: Hayek FA (ed) Collectivist economic planning. Routledge and Kegan Paul, London, pp 245-290

Black F, Scholes M (1973) The pricing of options and corporate liabilities. J Polit Econ 81:637-654

Boldyrev I (2016) Risk in general equilibrium: temporality and performativity in the ontology of finance. Soz Syst 20(1):9-22

Boldyrev I, Ushakov A (2016) Adjusting the model to adjust the world: constructive mechanisms in postwar general equilibrium theory. J Econ Methodol 23(1):38-56

Debreu G (1959) Theory of value. An axiomatic analysis of economic equilibrium. Yale University Press, New Haven

Drèze J (1974) Preface and Introduction. In: Drèze J (ed) Allocation under uncertainty: equilibrium and optimality. Macmillan, Houndmills

Duffie D, Sonnenschein H (1989) Arrow and general equilibrium theory. J Econ Lit 27(2):565-598

Foley D (1999) The ins and outs of late twentieth-century economics. In: Heertje A (ed) The makers of modern economics, vol 4. Edward Elgar, Cheltenham, pp 70-118

Grunberg E, Modigliani F (1954) The predictability of social events. J Polit Econ 62:465-478

Hands DW (1990) Grunberg and Modigliani, public predictions and the new classical macroeconomics. Res Hist Econ Thought Methodol 7:207-223

Hands DW (2016) Crossing in the night of the cold war: alternative visions and related tensions in western and soviet general equilibrium theory. Hist Econ Ideas 24:51-74

Harrison JM, Kreps DM (1979) Martingales and arbitrage in multiperiod securities markets. J Econ Theory 20:381-408

Herfeld C (2018) From theories of human behavior to rules of rational choice: tracing a normative turn at the Cowles Commission, 1943-54. Hist Polit Econ 50(1):1-48

Hirschman D, Popp Berman E (2014) 'Do economists make policies? On the political effects of economics'. Socio-Econ Rev 12(4):779-811

Hirshleifer J (1965) Investment decision under uncertainty: choicetheoretic approaches. Q J Econ 79:509-536

Hirshleifer J (1966) Investment decisions under uncertainty: applications of the state-preference approach. Q J Econ 80:252-277

Idabouk G (2010) Randomness, financial markets and the Brownian motion: a reflection on the role of mathematics in their interaction with financial theory after 1973. In: Suárez M et al (eds) EPSA philosophical issues in the sciences: launch of the european philosophy of science association. Springer, Heidelberg

Lange O (1936) On the economic theory of socialism: Part one. Rev Econ Stud 4:53-71

MacKenzie D (2006a) Is economics performative? Option theory and the construction of derivatives markets. J Hist Econ Thought 28(1):29-55

MacKenzie D (2006b) An engine, not a camera: how financial models shape markets. MIT Press, Cambridge 
Mirowski Ph (2002) Machine dreams: economics becomes a cyborg science. Cambridge University Press, New York

Myers SC (1968) A time-state-preference model of security valuation. J Financ Quant Anal 3:1-33

Radner R (1968) Competitive equilibrium under uncertainty. Econometrica 36(1):31-58

Radner R (1970) Problems in the theory of markets under uncertainty. Am Econ Rev 60:454-460

Rizvi SAT (1994) Game theory to the rescue? Contrib Polit Econ 13(1): $1-28$

Rizvi SAT (2006) The Sonnenschein-Mantel-Debreu results after thirty years. Hist Polit Econ 38:228-245

Rubinstein M (1987) Derivative assets analysis. J Econ Perspect $1(2): 73-93$

Rubinstein M (2006) A history of the theory of investments: my annotated bibliography. Wiley, New York

Savage LJ (1954/1972) The foundations of statistics. Dover, New York
Schliesser ES (2012) What happened to Knightian (and Keynesian) uncertainty post WWII? A philosophic history. https://ssrn.com/ abstract=2033117 or https://doi.org/10.2139/ssrn.2033117

Schliesser ES (2016) "Old ideas in pure theory," on the pre-history of performativity and reflexivity in the theory of markets under uncertainty. https://digressionsnimpressions.typepad.com/digre ssionsimpressions/2016/04/old-ideas-in-pure-theory.html

Tirole J (2017) Economics for the common good. Princeton Unviersity Press, Princeton

Varian H (1987) An arbitrage principle in financial economics. J Econ Perspect 1(2):55-72

Publisher's Note Springer Nature remains neutral with regard to jurisdictional claims in published maps and institutional affiliations. 